\title{
A revelação por excelência no paradoxo da presença de Deus na história: um possível diálogo entre Rudolf Bultmann e Karl Rahner
}

\author{
Revelation par excellence in the paradox of God's \\ presence in history: a possible dialogue between \\ Rudolf Bultmann and Karl Rahner
}

\section{La revelación por excelencia en la paradoja de la presencia de Dios en la historia: un posible diálogo entre Rudolf Bultmann y Karl Rahner}

Fabrício Veliq*

\begin{abstract}
RESUMO
Nesse artigo, propomos trabalhar as concepções antropológicas de Karl Rahner, a partir da obra de Gustavo Baena, e Rudolf Bultmann, mostrando suas possíveis convergências e divergências. Como ponto divergente, enquanto em Bultmann temos uma visão pessimista do ser humano, podemos perceber em Karl Rahner uma visão mais otimista do mesmo. Como ponto convergente, as duas antropologias culminam na figura de Jesus enquanto revelação por excelência através da presença de Deus na história.

Palavras-chave: Antropologia; história; revelação.
\end{abstract}

\begin{abstract}
In this article we propose to work with the anthropological concepts of Karl Rahner, from Gustavo Baena's work, and Rudolf Bultmann showing their convergences and divergences. As divergent point, while in Bultmann, we have a pessimistic view of human being, we can realize in Karl Rahner a more optimistic view of the same. As a converging point, the two anthropologies culminate in the figure of Jesus as revelation par excellence through a presence of God in history.

Keywords: Anthropology; history; revelation.

\section{RESUMEN}

En este artículo, proponemos trabajar las concepciones antropológicas de Karl Rahner, a partir de la obra de Gustavo Baena, y Rudolf Bultmann, mostrando sus posibles convergencias y divergencias. Como punto divergente, mientras que en Bultmann tenemos una visión pesimista del ser humano, podemos percibir en Karl Rahner una visión más optimista del mismo. Como punto convergente, las dos antropologías culminan en la figura de Jesús como revelación por excelencia a través de una presencia de Dios en la historia.

Palabras clave: Antropología; historia; revelación.
\end{abstract}

* Mestre em Teologia pela Faculdade Jesuíta de Belo Horizonte, Doutorando em teologia pela Faculdade Jesuíta de Filosofia e Teologia e Doutorando em Teologia pela Katholieke Universitëit Leuven. E-mail: fveliq@gmail.com. 


\section{Introdução}

O ser humano sempre foi um grande tema de diversas áreas do conhecimento. A filosofia, as ciências biológicas, a psicologia, todas, em algum momento, pensam o ser humano e sua relação seja com o meio em que vive, sua sociedade, seus anseios e seus desejos. A teologia não poderia ser diferente.

Ao falar da questão de Deus, um dos caminhos pelos quais se tem que passar é o caminho antropológico. Diversos autores, ao longo da história da teologia, falaram a respeito do ser humano. Desde a patrística até os dias atuais, a questão do ser humano, em relação a ele mesmo e em relação a Deus e ao mundo, tem sido objeto de inúmeros estudos e considerações por parte de diversos teólogos.

Esse artigo tem por intuito mostrar, em linhas gerais, dentro do pensamento de Baena, o pensamento sobre o ser humano na perspectiva de dois teólogos contemporâneos, Rudolf Bultmann e Karl Rahner, que culminará em visões semelhantes a respeito da pessoa de Jesus Cristo no pensamento dos dois teólogos.

\section{O pensamento de Bultmann sobre o ser humano}

O pensamento de Bultmann é fortemente influenciado pelo pensamento heideggeriano, que possui uma ontologia caracterizada pelo intuito de resgatar a pergunta pelo ser. Heidegger definirá como Dasein esse ente que pergunta pelo ser. Esse Dasein, no pensamento heideggeriano, é o "ente que sou cada vez eu mesmo" (HEIDEGGER, 1927, p. 62), sendo o modo de ser do Dasein um estar-no-mundo. Ao longo de sua obra, definirá o ser humano como um ser de angústia e cuidado, dizendo que "no cuidado está contido o ser do Dasein” (HEIDEGGER, 1927, p. 229).

Bultmann, ao analisar a compreensão cristã do ser, começa pela definição do que vem a ser o mundo, a contraposição entre mundo e "este mundo", referindo-se o primeiro à obra criadora de Deus e "este mundo" tendo satanás como seu senhor. Dessa forma, "este mundo", no Novo Testamento, é o "mundo da transitoriedade e da morte" (BULTMANN, 1999, p. 21), entendido como decorrência do pecado de Adão. Posteriormente, Bultmann definirá o que vem a ser a carne no contexto bíblico. Nesse ponto, faz-se importante lembrar que, mesmo utilizando conceitos heideggerianos em sua análise, nesse momento fala sob o aspecto bíblico do Novo Testamento.

O termo "carne", no pensamento bultmanniano, é a esfera do visível, do tangível, do disponível e do mensurável - sendo, por isso mesmo, transitório. Assim, o viver na carne, sobre o qual Paulo escreve em suas cartas, nada mais seria do que o viver a partir do disponível e do visível. Em sua análise do 
pensamento paulino, Bultmann observará que este via o ser humano como um ser preocupado acerca de seu futuro, com o intuito de obter algum tipo de segurança. O viver preocupado do ser humano, porém, segundo Bultmann, não é próprio de sua natureza, sendo, antes, um viver inautêntico.

Como, porém, seria possível uma vida autêntica no pensamento bultmanniano? Com o que vimos até agora, podemos inferir facilmente que o viver autêntico seria uma simples contraposição do viver inautêntico sendo, dessa forma, um viver "a partir do que é invisível e indisponível, renunciando a toda a segurança autocriada" (BULTMANN, 1999, p.23). Esse viver, segundo Bultmann, pode ser considerado um viver segundo o Espírito e uma vida vivida na fé.

"Fé", no pensamento bultmanniano, é esse abrir-se para o futuro, em uma entrega radical a Deus, esperando tudo Dele e nada de si, desprendendo de tudo aquilo que é disponível, ou seja, uma desmundanização, uma vida em liberdade. Essa desmundanização não deve ser entendida como movimento de ascese, mas, antes, como um distanciamento, um viver no mundo assumindo a postura do "como se não". Isso não implica que o crente, aquele que vive pela fé, tenha recebido uma nova natureza, ou que a mesma, preexistente, tenha sido libertada, uma vez que

[...] o que ele é na fé não é algo dado ou factual, um estado do qual estivesse seguro, de modo que a consequência seria um libertinismo; ou um estado o qual ele devesse temerosamente proteger, de modo que a consequência seria a ascese. A vida na fé não é estado algum, que pudesse ser descrito pelo indicativo. Antes, ao indicativo se acrescenta imediatamente o imperativo, isto é, a decisão da fé não é algo assumido de uma vez por todas, mas sim algo que deve se comprovar sempre nas situações concretas, sendo assumida de novo (BULTMANN, 1999, p.24).

No pensamento bultmanianno, liberdade representa uma liberdade para a obediência e o crer nada mais é que um ter sido apreendido, estando sempre em um estar a caminho entre o "ainda não" e o "mesmo assim já". Esse tipo de postura, como vimos mais acima, não indica uma ascese frente ao mundo, mas, antes, a postura de fé que, através do desprendimento do mundo, traz consigo uma abertura para a convivência humana.

Para Bultmann, há uma concordância de que tanto o Novo Testamento e a filosofia acreditam que o ser humano sempre só pode ser e tornar-se aquilo que já é. Assim, o ser humano só pode desenvolver um existir espiritual pelo fato de ser um espírito. No pensamento de Heidegger, isso fica claro, ao colocar que o ser humano se compreende quando percebe que é um ser-para-morte. No Novo Testamento, a ordem de Paulo para que os crentes sejam santos só 
é possível porque os mesmos já foram santificados. Portanto, o ser humano só pode conduzir uma vida autêntica porque essa já lhe foi atribuída e uma vez que já esteja nela. Ao contrário da filosofia, o Novo Testamento verá a queda do ser humano como algo no qual ele está e não pode fugir. Essa queda somente poderá ser revertida através do assumir a cruz de Cristo.

Crer na cruz de Cristo não significa mirar para um processo mítico, que transcorreu fora de nós e de nosso mundo, um vento objetivamente observável, que Deus nos imputa como acontecido em nosso favor. Ao contrário, crer na cruz significa assumir a cruz de Cristo como a própria, significa deixar-se crucificar com Cristo (BULTMANN, 1999, p.40).

Cruz e ressurreição no pensamento bultmanniano representam uma unidade. Dessa forma, a participação, tanto na cruz quanto na ressurreição, se dá na vida concreta, na liberdade, na luta contra o pecado e no despojar-se das obras das trevas.

De toda sua análise, percebe-se que "a palavra da proclamação se nos confronta como palavra de Deus, diante da qual não podemos fazer perguntas de legitimação, mas que apenas pergunta a nós se queremos crer nela ou não" (BULTMANN, 1999, p.45). Assim, a fé pascoal não se preocupa com uma questão histórico-fatual, mas, ao invés, anuncia que o ressurreto vem ao encontro do ser humano na palavra pregada, e somente nela, sendo a palavra de Deus a sóbria proclamação da pessoa de Jesus de Nazaré em sua significação salvífica, fato somente aceito pelo ser humano através da fé.

\section{Considerações sobre o ser humano no pensamento de Karl Rahner}

Rahner, assim como Heidegger, parte da pergunta pelo ser. Contudo, diferentemente de Bultmann, Rahner quer responder à pergunta: "é possível ao ser humano receber uma revelação da parte de Deus?”. Para responder a essa pergunta, primeiro propõe uma análise sobre a possibilidade de uma revelação divina. Sua primeira tese, de sua ontologia geral, define que "a essência do ser é conhecer e ser conhecido em uma unidade primitiva, a que nos leva a designar como um estar consigo, como estado de luminosidade subjetivada" (BAENA, 2011, p.1184). Esse modo de ser do ser humano é ser se conhecendo e na medida em que se conhece se torna iluminado para si.

Rahner defenderá que, conhecendo a si mesmo, o ser humano deduz, por analogia, um ser absoluto, que tem pleno conhecimento de si mesmo e autopossessão de seu ser: Deus. No pensamento rahneriano, a possessão do ser se mostra de duas formas: externando-se e no voltar para si. Dessa forma, sendo Deus aquele que tem a autopossessão de seu ser, é capaz de se externar, autocomunicando-se ao ser humano. 
O ser humano, para Rahner, existe enquanto ser concreto e ser transcendental. Partindo da teoria do conhecimento de São Tomás de Aquino, ele dirá que a essência do ser humano concreto está na atividade cotidiana fenomênica, sendo nela o lugar em que o ser humano se manifesta pela primeira vez, descobrindo, assim, sua essência e, dessa forma, é o conhecer e atuar que determina o essencial do ser humano. Porém, é na análise da transcendentalidade do ser humano que Rahner lançará os fundamentos para a possibilidade da revelação de Deus a esse ser humano.

No pensamento rahneriano, o ser humano tem a capacidade da transcendência $^{1}$ e, no voltar-se para si, através da antecipação ${ }^{2}$, da abstração $^{3}$, é possível conceber um ser absoluto que é possibilidade a priori de todo pensar e fazer humano e, por isso, a possibilidade real e última da existência do ser humano. Diante dessa antecipação do ser absoluto, o ser humano se vê como limitado. Em suas palavras:

O ser humano há de possuir uma abertura para a autoexpressão da absoluta possessão do ser por meio da palavra clara. Essa abertura há de pressupor o a priori para que tal palavra possa ser ouvida. [...] O ser humano é a absoluta abertura ao ser em geral, ou, dizendo em uma só palavra: o ser humano é espírito. A transcendência para o ser em geral é a estrutura fundamental do ser humano (RAHNER, 1976, p.79).

Rahner partirá de uma percepção fenomênica da existência do ser humano concreto existindo em sua facticidade cotidiana, sendo também um fenômeno interpretativo de onde se manifesta por si mesmo o âmbito das condições a priori de possibilidade dessa existência. Nesse âmbito de percepção reflexiva do a priori, por meio da análise do conhecimento, podemos entender o que Rahner denomina experiência transcendental ${ }^{4}$.

\footnotetext{
Transcendência, em Rahner, é a capacidade que o ser humano tem de estender-se de um singular para um ilimitado, ou seja, a capacidade de um "ir além" por meio do seu intelecto.

2 É o feito de estender-se a algo mais, dirigido ao ser e, portanto ao âmbito absoluto de seus possíveis objetos, é pelo que já em cada conhecimento particular se estende mais adiante do objeto particular, e com ele não o capta em seu fazer isolado e incomunicado, senão em sua limitação e referência à totalidade dos objetos possíveis (RAHNER, 1976, p.80). Esse processo de antecipação é um processo autônomo, sendo uma faculdade própria da essência humana.

3 Abstração, em Rahner, deve ser compreendida como os processos de objetivação, na subjetividade, de oposição do conhecer e do conhecido e, finalmente, o regresso do que conhece sobre si mesmo, ocorrendo dentro do modo de proceder do pensamento em sua tarefa própria de conhecer.

4 O ser absoluto para onde se move a tendência da antecipação humana não é experimentável em sua própria mesmidade pelo ser humano, mas somente é coexperimentado ou cossabido ou percebido nos distintos momentos do conhecimento humano, em particular naqueles que caracterizam o modo de abstração do conhecimento ativo sendo no fenômeno o lugar da manifestação, por si mesmo, do ser absoluto na antecipação
} 
O método antropológico transcendental rahneriano cumpre, assim, um de seus objetivos fundamentais, que é mostrar que o ser humano, em sua estrutura essencial, é feito para receber uma revelação divina. Nessa revelação, Deus comunica a si mesmo para a transcendentalidade do ser humano como espírito e esse a apreende na antecipação do ser absoluto como condição de conhecimento objetivo singular.

Até agora, na tentativa de resposta à pergunta inicial, temos dois pressupostos: em primeiro lugar, que Deus pode se revelar ao ser humano; em segundo, que o ser humano é feito para o recebimento de uma revelação ${ }^{5}$ divina.

Dessas considerações, é possível chegar à conclusão de que o ser humano, no pensamento rahneriano, é contingente, e o ser absoluto, dessa forma, é condição necessária para o existir humano. O Dasein só existe no ser absoluto e, dessa forma, deve colocar em ato aquilo que lhe é dado como ação livre.

Também em Rahner os temas da liberdade e da vontade se tornam importantes, uma vez que seria difícil responder à pergunta do poder de decisão do ser humano se ele está condicionado pela vontade do ser absoluto.

Para ele, o ser humano é um ser livre e capaz de decidir sobre aceitar a vontade divina. Contudo, a luminosidade do ser absoluto continua obscura ao ser humano finito. Não podemos esquecer que, no pensamento rahneriano, o ser absoluto de Deus tem seu próprio fundamento de ação livre da absoluta possessão de seu ser. Essa ação livre que está consigo é o amor. Assim, Deus cria enquanto sua ação criadora é ação livre, que estabelece a posição do ser humano.

Deus atua ou cria a estrutura essencial da existência do ser humano, executando a si mesmo nela o fundamento de seu próprio ser infinito, a saber, a possessão absoluta de seu ser, estando ele mesmo em si mesmo; portanto, o mais íntimo de seu ser é esta ação livre, luminosa por si mesma. Precisamente esta mesma ação livre, divina é a que sucede na posição do ser humano, como ser contingente, ou seja, Deus cria o ser humano acontecendo nele, como dom de si, outorgando-se com a absoluta possessão do seu ser no ente finito (BAENA, 2011, p. 1212).

Dessa forma, o amor como ação é vontade livre. Deus cria o ser humano amando a si mesmo, no ser humano. E esse mesmo amor a si mesmo, como poder criador que coloca o finito, é onde compreende o ser humano em sua autocomunicação com ele. Esse amor de Deus cria e estabelece a posição humana. Assim, a forma pela qual o ser humano assume a vontade de Deus

Aquilo que é, de per si, impenetrável a todo ser finito, que não pode ser antecipado por nenhum conhecimento, ou seja, a impenetrabilidade da liberdade de Deus, sua vontade em sua automanifestação como Deus pessoal à criatura. 
como sua evidencia-se quando, em um ato único da específica vontade de Deus, a revelação transcendental se manifesta em ato categorial.

Portanto, sendo o ser humano livre e Deus sendo livre, a revelação específica ${ }^{6}$ acontece em uma síntese histórica que resulta do encontro de agentes livres. Essa revelação específica se manifesta, dessa forma, fenomenicamente, nas operações categoriais livres e autênticas que o ser humano faz em seu existir concreto.

Esse ser humano, contudo, não vive sozinho no mundo. Seu viver concreto não é independente da comunidade na qual o mesmo está inserido. Rahner mostrará que a comunidade é o lugar histórico de uma possível revelação da parte de Deus.

Posto que é um entre muitos não pode realizar individualmente a totalidade de suas possibilidades de ser, nem em um só ato formal, nem isolado dos outros de seu mesmo gênero, senão em uma particular relação responsável com eles e dentro do mundo espaço temporal (BAENA, 2011, p.1229).

Sua análise termina mostrando que

o ser humano, enquanto espírito cognoscente é a síntese histórica onde sucede, em um único e unificado ato do conhecimento humano, o fenômeno, como momento intrínseco desse mesmo conhecimento e a transcendência do ser humano para o ser absoluto em uma relação necessária (BAENA, 2011, p.1235).

Esse fenômeno, no entanto, é passível de significação e interpretação. Assim, tem como base as possibilidades de significação em três proposições, introduzindo, assim, a hermenêutica do fenômeno.

A primeira proposição mostra que o ser em geral somente se revela ao ser humano no fenômeno. A segunda afirma que é por meio do fenômeno que o ser humano descobre o ser em geral. E a terceira ensina que todo ente pode fazer-se presente no horizonte do fenômeno humano mediante a palavra.

Através da hermenêutica do fenômeno, Rahner mostra que os sinais da revelação de Deus só podem ocorrer por meio do fenômeno: "Deus pode fazer acessível sua própria identidade ao ser humano mediante a palavra

6 Importante lembrar que, para Rahner, na revelação específica concorrem três momentos dentro de uma mesma síntese histórica: 1 - a revelação transcendental, que é o ato criador no qual Deus se autocomunica à existência do ser humano como absoluta vontade sobre ele; 2 - a revelação categorial, que é a livre decisão do ser humano ao interpretar faticamente essa vontade absoluta, realizando sua existência categorialmente e de maneira autêntica, por meio de ações intencionais livres; 3 - o concretamente revelado, que vem a ser a vontade de Deus sobre o ser humano concreto. 
sensivelmente manifestada por meio do fenômeno" (BAENA, 2011, p.1238). Essa palavra, porém, é um signo conceitual e necessita ser interpretada. Com isso, percebemos que, no pensamento de Rahner, é no fenômeno que o ser humano escuta como palavra uma possível revelação de Deus.

Com toda essa análise, Rahner conclui que a apreensão fenomênica das determinações categoriais é o lugar onde o ser humano pode escutar como palavra a orientação transcendental de Deus, onde Ele revela sua vontade ou ato criador a cada espírito humano e, assim, as próprias determinações categoriais são a objetivação histórica da revelação transcendental.

Em Jesus, temos a autocomunicação de Deus aos seres humanos, uma vez que ele é a interpretação da revelação transcendental e, por ser isso, é também interpretação categorial em sua existência histórica. Jesus, então, é a palavra última e definitiva que Deus pronuncia a respeito da sua vontade sobre o ser humano. Ou seja, a revelação por excelência.

\section{Conclusão}

Das colocações feitas, podemos notar duas grandes diferenças entre o pensamento de Bultmann e o pensamento de Karl Rahner. Em primeiro lugar, enquanto Bultmann está preocupado com uma interpretação da bíblia enquanto revelação divina, Rahner está preocupado com a possível revelação de Deus ao ser humano na história.

Em segundo lugar, enquanto Bultmann tem sua base filosófica em Heidegger, Rahner utilizará como base a metafísica do conhecimento de São Tomás de Aquino.

Poderíamos elencar outro ponto divergente no pensamento desses dois teólogos. Enquanto Bultmann, luterano e marcado pela teologia de Lutero, tem uma visão bastante pessimista a respeito do ser humano, ou seja, o ser humano enquanto pecador, distanciado de Deus, que depende da graça divina para obter salvação e redenção, Rahner apresenta uma visão mais otimista do ser humano, enquanto um ser que foi criado, em sua essência, como possível recebedor da revelação divina.

Da mesma forma que podemos achar pontos divergentes, há pontos convergentes. Dentre os vários que podemos elencar, apontaremos dois pontos de convergência desses pensamentos: em primeiro lugar, a figura da decisão do ser humano e, em segundo, a questão cristológica. A questão da liberdade humana é tratada de forma bem rápida, tanto no texto bultmanniano quanto no texto rahneriano. Para Bultmann, como vimos, o ser humano não consegue, por si mesmo, apreender sua vida autêntica, estando totalmente caído. Esse cair consiste na autossuficiência do ser humano que o Novo 
Testamento chamará de pecado. Porém, mesmo caído, o ser humano ainda pode decidir se se lançará na dependência de Deus através do ato de fé ou não. Em Rahner, mesmo o ser humano tendo em si os elementos necessários para uma possível revelação de Deus, ainda assim, "em toda decisão livre o ser humano opta em sua própria existência sobre si mesmo" (BAENA, 2011, p.1221). Dessa forma, o ser humano é um agente livre para determinar seu modo de viver e sua relação com o Criador. O segundo ponto é que, tanto Bultmann quanto Rahner, convergem para a mesma conclusão: de que o viver autêntico do ser humano se dá através da pessoa de Jesus Cristo.

Enquanto em Bultmann o viver autêntico se manifesta no entregar-se a Deus e em um viver pela fé, a partir de uma decisão livre, abandonando o viver inautêntico e preocupado, percebemos, em Rahner, que o ser humano vive para Deus quando a experiência transcendental se efetiva em um ato categorial por sua livre vontade, exercendo sua liberdade.

No Jesus desses dois teólogos, percebemos a marca dessas duas teorias. Jesus vive um viver autêntico em total dependência do Pai, bem como é a plena interpretação da revelação transcendental e categorial em sua existência histórica. Assim, podemos perceber que, no paradoxo da presença de Deus na história, encontra-se a revelação por excelência.

\section{Referências bibliográficas}

BAENA, Gustavo. Feomenologia de la revelación. Teologia de la Bíblia y hermenéutica. Estela: Verbo Divino, 2011.

BULTMANN, Rudolf. Demitologização. São Leopoldo: Sinodal, 1999.

HEIDEGGER, Martin. Ser y tiempo. Edición electrónica. Chile. Disponível em: $<$ http: $\backslash \backslash$ www.philosophia.cl.html>. Acesso em: 08 nov. 2012. [Nota do editor: a obra pode ser encontrada em: http://www.afoiceeomartelo.com.br/posfsa/Autores/Heidegger,\%20Martin/ Heidegger\%20-\%20Ser\%20y\%20tiempo.pdf - acessada em 18/12/2017]

RAHNER, Karl. Oyente de la palabra. Barcelona: Herder, 1976.

Submetido em: 12-7-2017

Aceito em: 11-12-2017 